\title{
Precision of Measurement of Water Vapor Resistance of Fabrics with Different Surface Roughness by a Skin Model
}

\author{
Lubos HES $^{1}$ (D) 0000-0002-0734-8603 \\ Vinay Kumar MIDHA ${ }^{2}$ (DD 0000-0002-1630-9382 \\ ${ }^{1}$ Technical University of Liberec, Faculty of Textile Engineering, Liberec, Czech Republic \\ ${ }^{2}$ Dr B R Ambedkar National Institute of Technology, Jalandhar, India
}

\begin{abstract}
Skin models are used for determination of water and thermal resistance of fabrics. Measurement in these instruments starts with determination of water vapour resistance of a boundary layer above the sweating hotplate. In the second step, the hotplate is covered by the tested fabrics and the instrument measures WV resistance of the fabric and that of boundary layer. Afterwards, the difference between these measurements presents the required WV resistance of the measured fabric, provided that WV resistance of the boundary layer is in both measurements identical. However, fabric surface roughness may change WV resistance of the boundary layer in the second measurement. In the paper, the effect of the fabric surface on measurement precision is theoretically analysed and experimentally verified by procedure, which provides same air surface friction during both steps of the measurement. Experiments confirmed certain but small effect of the fabric surface roughness on the measurement precision.
\end{abstract}

\author{
ARTICLE HISTORY \\ Received: 03.01.2021 \\ Accepted: 01.09.2021
}

\section{KEYWORDS}

Water vapor resistance, textile fabric, skin model, measurement precision, surface roughness

\section{INTRODUCTION}

In last decades, lot of attention is paid to measurement of parameters of thermo-physiological comfort of textile fabrics, namely fabrics with high added value used for sport and protection. The most important standard for testing of thermal and water vapour resistance of fabrics $R_{c t}$ and $R_{e t}$ is the ISO 11092, which present most important parameters for characterisation of thermophysiological comfort of clothing [1-3].

The original related instrument called "Skin Model" consists of heated metallic plate surrounded on most of its surface by a thermal insulation layer kept electronically at the same temperature. Due to this isothermal arrangement, no heat is transferred out of this plate, except the heat passing through the only free surface. Free surface of this measuring plate covered by the porous layer is exposed to parallel air flow of $1 \mathrm{~m} / \mathrm{s}$ velocity moving in the special wind channel (Figure 1).

$$
\begin{aligned}
& \text { air flow } \rightarrow \rightarrow \rightarrow \rightarrow \rightarrow \rightarrow \rightarrow \rightarrow \mathrm{q}_{\mathrm{conv}} \rightarrow \text { fan } \\
& \text { mass flow } \quad \uparrow \uparrow \uparrow \uparrow \uparrow \uparrow \uparrow \quad \text { qevap } \rightarrow \text { fan } \\
& \text { temp. sensor } \rightarrow \text { wetted porous body }
\end{aligned}
$$

Figure 1. Heat and mass transfer in a skin model

When measuring the fabric thermal resistance $R_{c t}$, the air temperature in the channel is kept at $20^{\circ} \mathrm{C}$, and the measuring plate is dry. First, the power $\mathrm{H}$ supplied to the hotplate in order to heat the measuring system to temperature $35^{\circ} \mathrm{C}$ is measured. Then, the tested fabric is placed on the porous layer of the measuring plate and the electric power expressing heat passing through the system to outer air is measured again. Edges of the tested sample are placed on the mentioned surrounding isothermal envelope, in order to avoid heat loses from the sample in

To cite this article: Hes L, Midha VK. 2021. Precision of Measurement of Water Vapor Resistance of Fabrics with Different Surface Roughness by a Skin Model. Tekstil ve Konfeksiyon, 31(3), 214-219. 
the enviroment of different temperature.

When evaluating the water vapour resistance $\mathrm{R}_{\mathrm{et}}$, both the measuring plate and the air are kept at the temperature $35^{\circ} \mathrm{C}$ (to achieve the isothermal conditions) and the porous layer is continuously filled with water. Then, again the heating power $\mathrm{H}$ without and with the specimen is measured and saved. In the second step, the specimen is inserted between the measuring plate and the wind channel and the steadystate and the heating power $\mathrm{H}$ is recorded again. All the power values then serve for the calculation of thermal and water vapour resistance values according to the simple formulas presented in the ISO 11092.

The small Skin model PERMETEST used in this study works on the same principle, just the amount of heat power passing through the measuring surface is measured directly by a special calibrated sensor. Other details about the device are presented elsewhere [4].

\section{MATERIAL AND METHOD}

\subsection{Principal Disadvantage of the ISO 11092 Testing Method}

The proper principle of this method for determination of both thermal and water vapour resistance levels is based on subtracting the boundary layer resistance $R_{c t}$ or (corresponding to smooth free measuring plate) from the total resistance consisting of fabric resistance and fabric boundary layer resistance. However, the fabric boundary layer resistance can differ from the resistance of boundary layer adhered to instrument measuring plate. This difference can result from different air friction against the fabric surfaces with different surface profiles (sweaters, blankets), which affects the degree of turbulence and hence the thickness of the boundary layer. As the boundary layer thickness divided by a diffusion coefficient (or by a thermal conductivity) presents approximately its water vapour resistance (or thermal resistance), the measured levels values of these principal comfort parameters can differ from the real ones. Certain effect of the fabric surface roughness on the measured thermal and evaporation resistances caused by varying fabric structure was observed in $[5,6]$.

Thus, these uncertainties in the determination of water vapour resistance and thermal resistance of boundary layers adhered to the free measuring surface and to surface of the tested fabrics may theoretically cause certain measurement imperfection. In next research we will investigate, whether these imperfections are substantial or not. From large practical use of the ISO 11092 follows, that in most cases the possible reduction of the measurement precision does not prevent the successful application of the ISO 11092 in many textile areas [5].

\subsection{Reynolds Analogy for Boundary Layers}

This analogy correlates the air friction coefficient $f$, Reynolds dimensionless number $\mathrm{Re}$ and dimensionless numbers $\mathrm{Nu}$ and $\mathrm{Sh}$, which serve for calculations of heat and mass transfer coefficients. The analogy applicable for laminar flow of fluids has the following form [7]:

Re.f $=2 \mathrm{Nu}=2 \mathrm{Sh}$

The abovementioned Reynolds number is given by relationship

$$
\operatorname{Re}=\mathrm{u} . \mathrm{d} / \mathrm{v}
$$

where $\mathrm{u}$ is the air velocity above the tested sample, which in all Skin models reaches $1 \mathrm{~m} / \mathrm{s}, \mathrm{d}$ is the hydraulic diameter of the air channel $(0,068 \mathrm{~m}$ in the used PERMETEST instrument) and $v$ is kinematic viscosity of air $\left(1,71.10^{-5}\right.$ Pa.s). Thus, from the calculations executed in the study ${ }^{5}$ follows, that Reynolds number in a measuring channel reaches the value $\operatorname{Re}=5780$, which confirms the turbulent character of the air flow in this instrument. The limit RE number for laminar flow is 2300. However, all these calculations are based on a presumption, that the velocity profile is fully developed. The commonly known Bussinesq relation which requires a length (distance) $\mathrm{D}$ of a flow in a channel longer than $D>0,065$. d.Re for the development of a full laminar velocity profile is applicable for the laminar flow only. According to the source [7], for the above confirmed turbulent flow the full velocity profile in a channel can be developed much earlier, within a distance $\mathrm{D}$ longer than 10 multiple of the hydraulic diameter $\mathrm{d}$ of the channel, in means here $0,68 \mathrm{~m}$.

However, the distance $\mathrm{d}$ between a pressured air outlet (perforated plate) and a measuring hotplate in the measuring cannel (zone) of Skin models, where the air runs parallely along the tested fabric surface, is lower than 0,5 $\mathrm{m}$. Thus, within the short distance between the air outlet and a tested sample, only the laminar boundary layer is developed, as it can be seen on the below picture Figure. 2.

Thus, the above principle of the effect of air friction $f$, by which the dimensionless heat transfer coefficient $\mathrm{Nu}$ and mass transfer coefficient Sh depend on this air friction coefficient $f$, which is proportional to the fabric surface roughness, is applicable here:

$\mathrm{Nu}=\operatorname{Re} . \mathrm{f} / 2, \mathrm{Sh}=\operatorname{Re} . \mathrm{f} / 2$

As already mentioned, Nusselt and Sherwood numbers $\mathrm{Nu}$ and Sh present dimensionless forms of heat and mass transfer coefficients $\alpha$ and $\beta_{\mathrm{c}}$, given by equations (4):

$\mathrm{Nu}=\alpha \mathrm{d} / \lambda$ and $\mathrm{Sh}=\beta_{\mathrm{c}} \mathrm{d} / \mathrm{D}_{\mathrm{a}}$ 


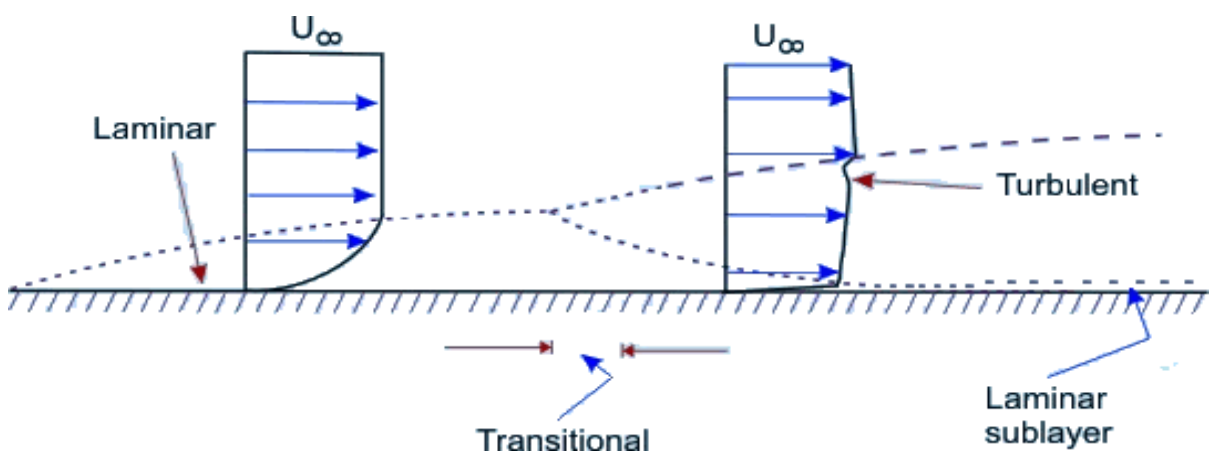

Figure 2. Development of boundary layer above the bottom of the measuring channel in Skin models (https://nptel.ac.in/content/storage2/courses/112104118/lecture-32/32-3_lami_turb_trans.htm)

where $\lambda$ is the coefficient of thermal conductivity and $D_{a}$ means the coefficient of water vapour diffusion in air (in this case). Here, the mass transfer coefficient $\beta_{c}$ is destined for driving force expressed in water vapour concentration difference. When driving force is expressed as a difference of water vapour partial pressures, a transformation coefficient (based on the common gas equation) must be used:

$\beta p=\beta_{c} /($ r.T $)=$ Sh. $D_{a} /($ d.r.T $)=$ f. Re. $D_{a} /(2$. d.r.T $)$

Here, $\mathrm{r}$ means gas constant for air having value $461, \mathrm{Jkg}^{-1} \mathrm{~K}^{-1}$, $\mathrm{T}$ is mean temperature of the mass transfer process in $\mathrm{K}$.

Now, it should be explained, why the correlation between the air friction and the heat and mass transfer coefficients important. That is because the $\mathrm{R}_{\text {eto }}$ and $\mathrm{R}_{\text {cto }}$ resistances created by boundary layer on the fabric surface are inverted values of heat and mass transfer coefficients $\alpha$ and $\beta_{c}$, as given in Equation (6):

$\mathrm{R}_{\text {cto }}=1 / \alpha$ and $\mathrm{R}_{\text {eto }}=1 / \beta_{\mathrm{p}}$

Thus, the fabric surface roughness, which strongly influences the air friction coefficient $f$, theoretically influences the $\mathrm{R}_{\mathrm{e}} \mathrm{t}$ and $\mathrm{R}_{\mathrm{ct}}$ levels also and in this way affects the measurement precision. For the purpose of next extension of this study (determination of evaporation resistances $R_{\text {eto }}$ and $R_{\text {et }}$, mass transfer coefficient $\beta_{p}$ $\left[\mathrm{kg} / \mathrm{m}^{2} / \mathrm{s}\right]$ can be determined from the following experimental equation applicable for a laminar flow along a flat plate [6] instead of the Equation (6), as it is quite uneasy to measure the air friction coefficient:

$$
\begin{aligned}
& \mathrm{Sh}=0,664 \cdot \mathrm{Re}^{0,5} \cdot \mathrm{Sc}^{0,33} \quad \beta_{\mathrm{c}}=\mathrm{Sh} . \mathrm{D}_{\mathrm{a}} / \mathrm{d} \\
& \beta_{\mathrm{p}}=0,664 \cdot \mathrm{Re}^{0,5} \cdot \mathrm{Sc}^{0,33} \cdot \mathrm{D}_{\mathrm{a} \cdot \mathrm{d}^{-1} \mathrm{r}^{-1} \cdot \mathrm{T}^{-) 1}} \\
& \mathrm{R}_{\text {eto }}=1,51 \mathrm{Re}^{-0,5} \cdot \mathrm{Sc}^{-0,33} \cdot \mathrm{D}_{\mathrm{a}}^{-1} \mathrm{~d} \cdot \mathrm{r} \cdot \mathrm{T}
\end{aligned}
$$

The Sc dimensionless number used in the above equations characterize the boundary layer, in which mass (here water vapour) is transferred by diffusion and convection [7]. From a study [8] follows, that for conditions used in the PERMETEST tester the $R_{\text {eto }}$ reaches approx. $6,5 \mathrm{~m}^{2} \mathrm{~Pa} / \mathrm{W}$.

In the next part of the study, the effect of the surface roughness on the determined values of evaporation resistance of selected fabrics [8-10] will be verified experimentally.

\subsection{Modified Method of Determination of Fabrics Water Vapour Resistance}

In the first step of this new method, the porous layer (measuring surface) of the skin model instrument is covered by one tested fabric characterized by its thermal resistance $\mathrm{R}_{\mathrm{ct}}$ and water vapour resistance Ret. Then, heating power $\mathrm{H}$ (in Watts in standard Skin models) or cooling flow $\mathrm{q}_{\text {cool, } \mathrm{f}+\mathrm{bl}}$ $\left(\mathrm{W} / \mathrm{m}^{2}\right.$ in the Permetest skin model) are used for calculation of the complex "boundary layer", $\mathrm{R}_{\mathrm{et}}+\mathrm{R}_{\mathrm{eto}}$ :

$$
\mathrm{R}_{\mathrm{et}}+\mathrm{R}_{\mathrm{eto}}=\left(\mathrm{p}_{\mathrm{parc}, \text { sat }}-\mathrm{p}_{\mathrm{parc}, \text { air }}\right) / \mathrm{q}_{\mathrm{cool} 1}
$$

In the second step, the measuring surface of the Skin mod el is covered by two layers of the tested fabric:

$2 R_{\text {et }}+R_{\text {eto }}=\left(p_{\text {parc, sat }}-p_{\text {parc, air }}\right) / q_{\text {cool } 2}$

In the third step, the instrument calculates the difference between both measurements:

et $=\left(p_{\text {parc, sat }}-p_{\text {parc, air }} /\left(q_{\text {cool 2 }}-\mathrm{q}_{\text {cool 1 }}\right)\right.$
$=\left(2 \mathrm{R}, 2_{\text {et }}+R_{\text {eto }}\right)-\left(R_{\text {et }}+R_{\text {eto }}\right)$

Formally, water vapour resistance and thermal resistance values, were determined according to the ISO 11092 procedure, but this time, the air flow passes along the same measuring surface (textured fabric surface), therefore, same boundary value resistance $R_{\text {eto }}$ and $R_{c t o}$ appear in the determination of the $R_{\text {et }}$ and $R_{\text {ct }}$ levels. It is expected, that this procedure excludes all the boundary layer effects, thus being scientifically correct.

\subsection{Tested Samples}

In order to confirm the above findings, $R_{e t}$ values $\left[\mathrm{m}^{2} \mathrm{~Pa} / \mathrm{W}\right]$ of 7 various commercial woven fabrics differing in their surface structure were determined by means of the PERMETEST Skin model. The fabrics consisted of $100 \%$ cotton, $100 \%$ polyester and $100 \%$ polypropylene [8] - see the Table 1

The use of cotton in this research is given by general importance of cotton fabrics in clothing. The other used 
fabric, consisting of synthetic polypropylene, exhibits low moisture sorption, which increases the measurement repeatability. The requirement of high repeatability also avoids the selection of knitted structures, as knits suffer from higher mass variation. Before testing, samples were washed at $60^{\circ} \mathrm{C}$ with a detergent. Their surface roughness was determined by the KES instrument - see the example of these measurements on the Figure 5. First measurements step followed the ISO 11092 Standard, the second series of measurements was based on the new $1+2$ layers method. In the last series of measurements multiple layers of the polypropylene fabrics were used, in order to verify the linearity of the new method.

Table 1. Parameters of the tested woven samples

\begin{tabular}{clccc}
\hline Sample code & \multicolumn{1}{c}{ Composition } & Structure & Square mass $\left[\mathbf{g} / \mathbf{m}^{\mathbf{2}}\right]$ & Roughness $[\boldsymbol{\mu m}]$ \\
\hline 1.1 & cotton structured & waffle weave & 240 & 5,0 \\
1.2 & cotton structured & corduroy & 190 & 1,9 \\
1.3 & cotton smooth & plain & 270 & 1,8 \\
2.1 & polyester smooth & plain & 300 & 1,9 \\
2.2 & polyester structured & plain & 300 & 3,3 \\
3.1 & polypropylene smooth & twill & 230 & 2,0 \\
3.2 & polypropylene smooth & plain & 220 & 2,0 \\
\hline
\end{tabular}
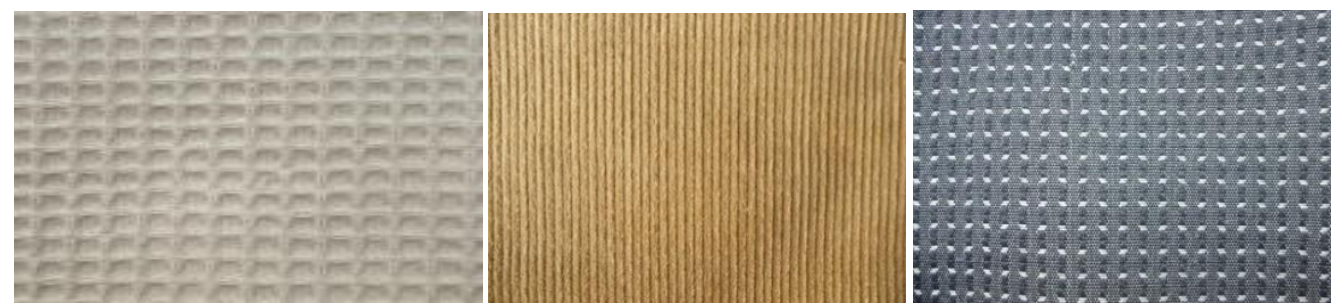

Figure 3. Samples No. 1.1, 1.2 and 2.2 with surface texture with increased friction against the air flow
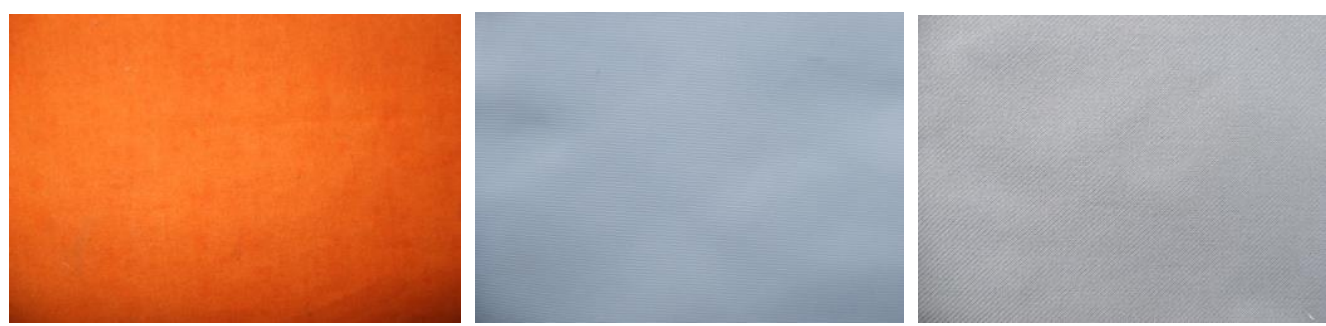

Figure 4 Samples No. 1.3, 2.1 and 3.1 with smooth surface with low friction against the air flow

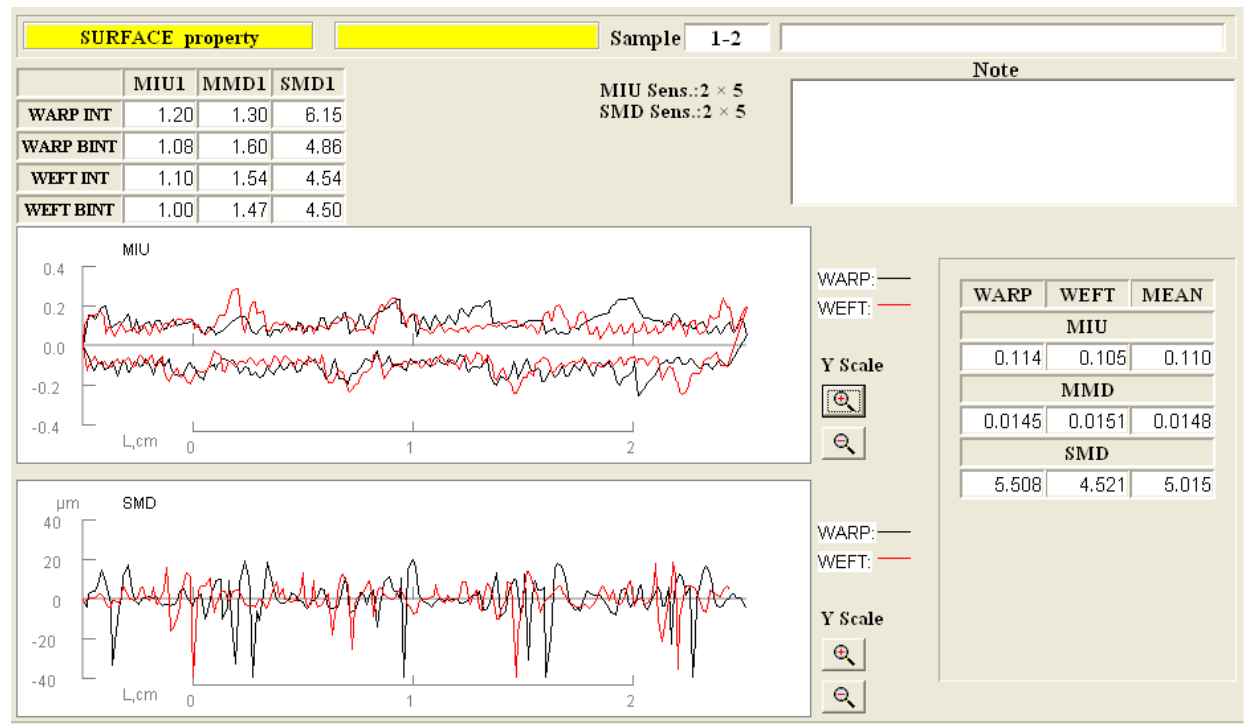

Figure 5. Diagrams of surface roughness and friction coefficients of the sample 1.1. from the KES tester 


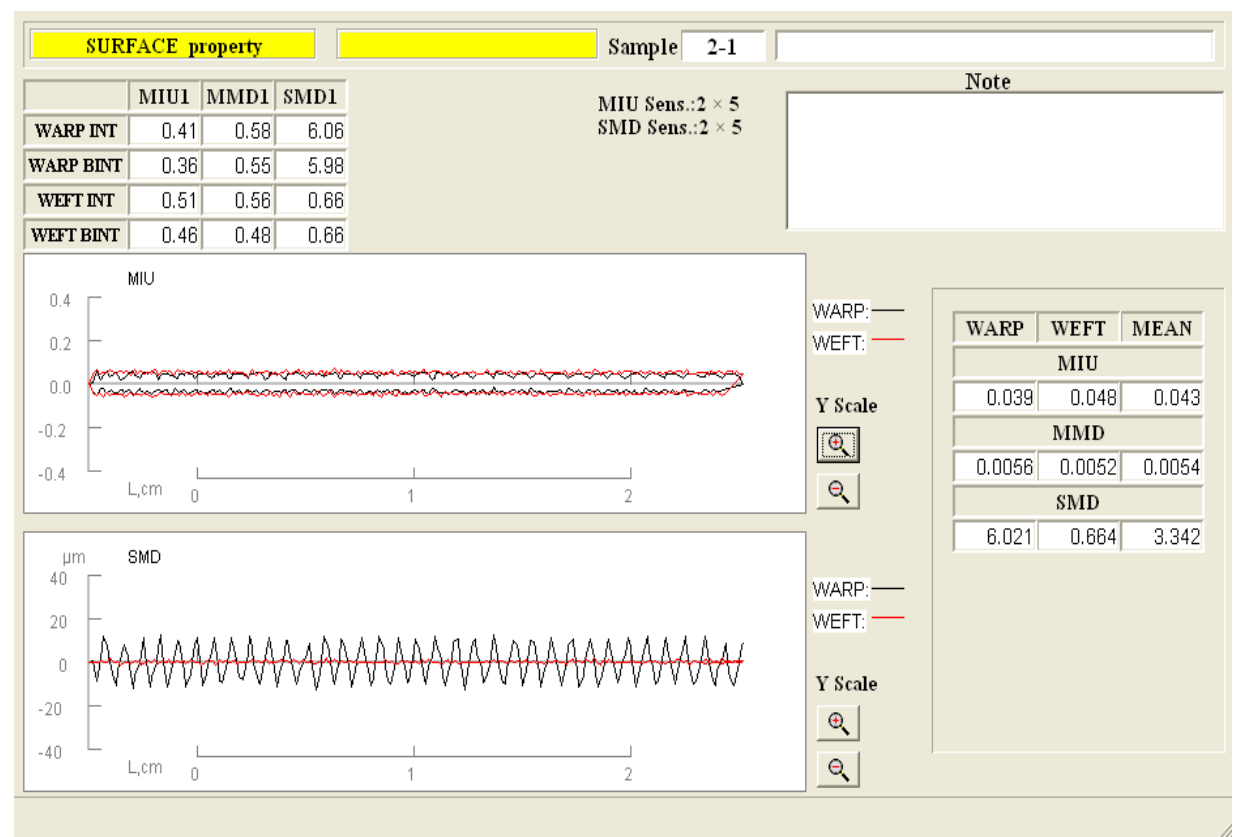

Figure 6. Diagrams of surface roughness and friction coefficients from the KES tester of the sample 2.2.

\section{RESULTS AND DISCUSSION}

$\mathrm{R}_{\mathrm{et}}\left(\mathrm{m}^{2} \mathrm{~Pa} / \mathrm{W}\right)$

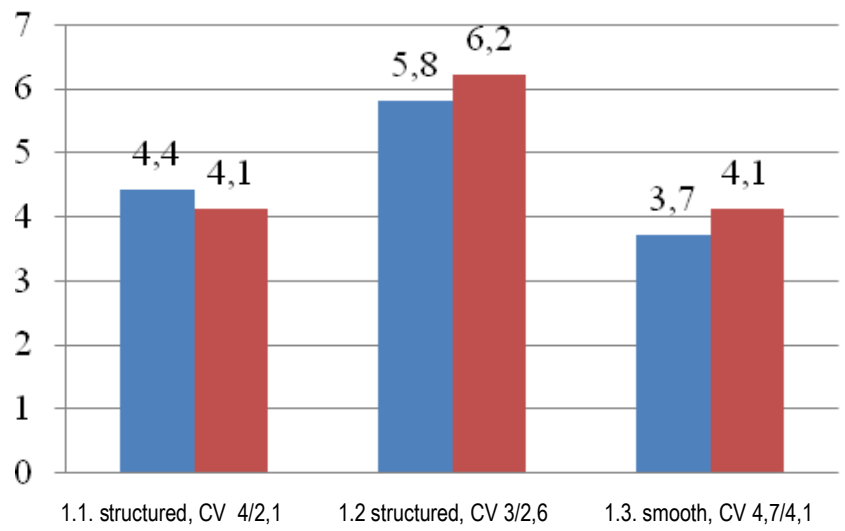

Figure 7. $\mathrm{R}_{\mathrm{et}}$ of cotton samples. Simple sample is in blue, double one is in red. CV is Variation Coef. in (\%).

$\mathrm{R}_{\mathrm{et}}\left(\mathrm{m}^{2} \mathrm{~Pa} / \mathrm{W}\right)$

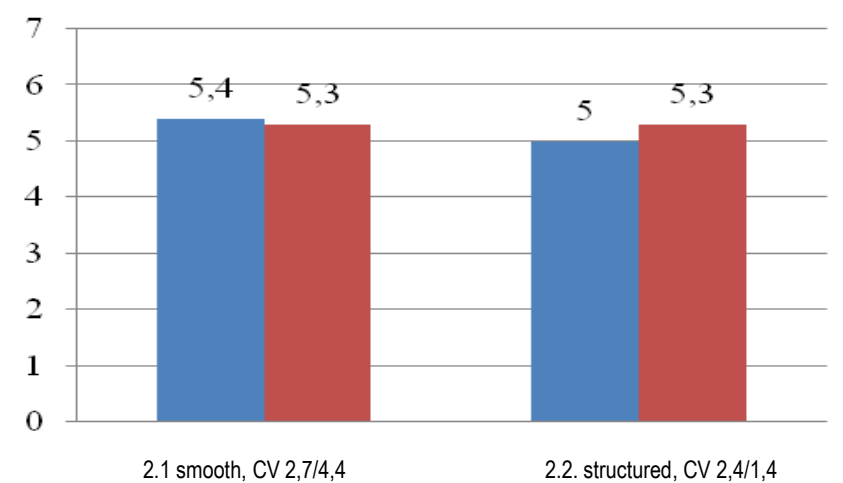

Figure 8. $R_{\mathrm{et}}$ of polyester samples. Simple sample is in blue, double sample is red.
$\operatorname{Ret}_{\mathrm{et}}\left(\mathrm{m}^{2} \mathrm{~Pa} / \mathrm{W}\right)$

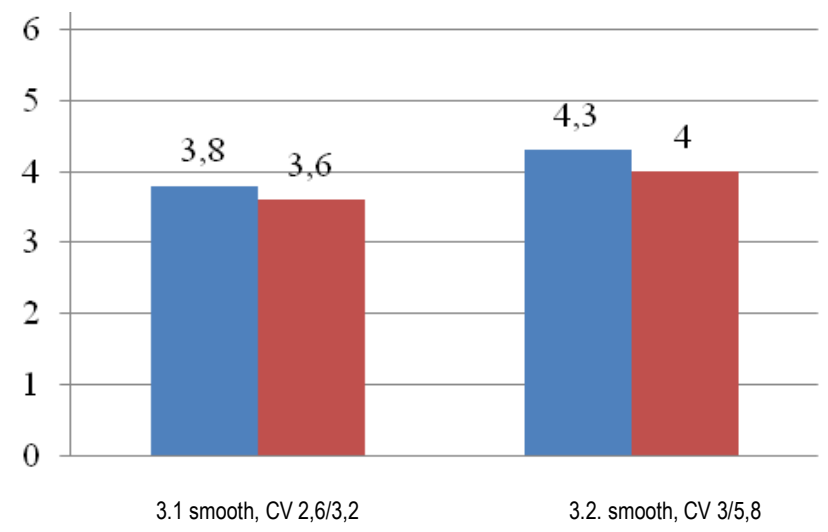

Figure 9. Ret $_{\text {ef }}$ polypropylene samples. Simple sample is in blue, double sample is red.

It was found, that for smooth samples, the new $1+2$ method provides lower levels (2-7\%) of the evaporation resistance $\mathrm{R}_{\mathrm{et}}$, whereas for the structured samples with higher surface friction higher levels (6-10\%) of $\mathrm{R}_{\mathrm{et}}$ are determined. Thus, the theoretical considerations, which indicate certain imperfections of the ISO 11092 Standard, are probably correct.

The objective of the last research step is to verify, whether the linear increase of the total thickness of multilayer fabric system would cause the corresponding linear increase of evaporation resistance of the fabric system. In order to exclude the possible effect of moisture accumulated in fabrics and the effect of surface hairiness, smooth hydrophobic polypropylene fabrics were used in the testing. The use of smooth fabrics without texture would also avoid the creation of hollow places between the multilayer fabrics, which might provide additional uncontrolled thermal resistance. The results are displayed on the Figure 10 . 


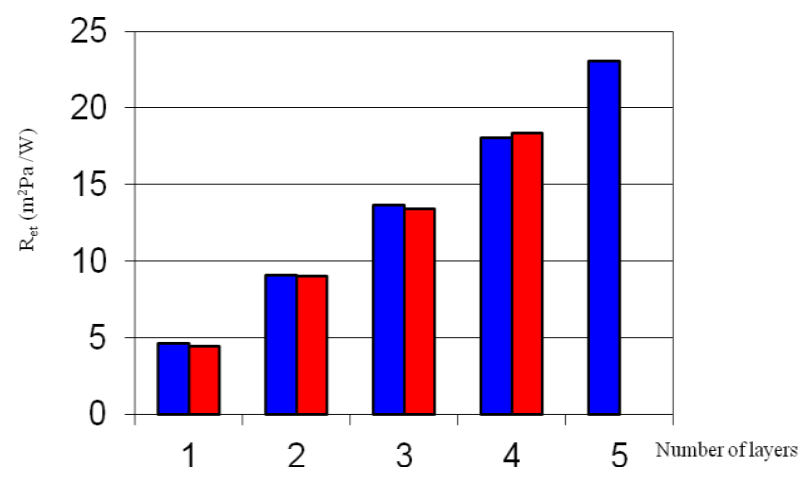

Figure 10. $\mathrm{R}_{\mathrm{et}}$ of smooth polypropylene samples No. 3.2. Simple sample is in blue, multiple sample is in red. CV was always lower then 5,0\%. The linear increase of the evaporation Ret resistance with the number of layers confirms the correctness of the presented method of measurement and the linearity of the used testing instrument [10].

The results shown on the Figure 10 indicate first, that the contact resistances between the fabric layers do not reduce the measurement precision substantially - if the resistance values are linked with the line, in both cases the lines pass through the initial point $\mathrm{x}=0, \mathrm{y}=0$. More important result is, that for smooth fabrics, the differences between the classical and new method are almost negligible [8].

\section{REFERENCES}

1. Mukhopadhyay A, Midha VK. 2008. A review on designing the waterproof breathable fabrics part I: Fundamental principles and designing aspects of breathable fabrics. Journal of Industrial Textiles $37(3), 225-262$

2. Ertekin G, Marmaralı A. 2011. Heat, air and water vapor transfer properties of circular knitted spacer fabrics. Tekstil ve Konfeksiyon 21(4), 369-373.

3. Matusiak M. 2006. Thermal insulation properties of single and multilayer textiles. Fibres \& Textiles in Eastern Europe 14, 5(59), 98112.

4. Hes L, Araujo M. 2010. Simulation of the effect of air gaps between the skin and a wet fabric on resulting cooling flow. Textile Research Journal 80(14), 1488-1497.

5. Özdemir H. 2017. Thermal comfort properties of clothing fabrics woven with polyester/cotton blend yarns. AUTEX Research Journal 17(2), 135-141

6. Özdemir H. 2017. Permeability and wicking properties of modal and lyocell woven fabrics used for clothing. Journal of Engineered Fibers and Fabrics 12(1), 7-21.

\section{CONCLUSION}

In the study, the effect of the surface roughness of selected textile fabrics tested by a Skin model on the determined water vapour resistance of these fabrics. Firstly, the fabrics were tested according to the ISO 11092 standard. In the second series of measurement, modified testing method was used, where the measuring surface of the Skin model was covered by one layer of the tested fabric and then by double layered fabric, in order to avoid the effect of the fabric surface on the determined values of fabric water vapour resistance. It was found, that when testing the structured samples by a new method, the Ret values were 6-10\% higher than at the standard testing. For smooth samples, new method displayed lower Ret values (from 2\% to $7 \%$ ). However, from the large practical use of the ISO 11092 follows, that in most cases the possible reduction of the measurement precision does not prevent the successful application of the ISO 11092 in textile areas [11]. It can be concluded, that at fabrics with common surface roughness, the boundary layer thickness is probably higher than the surface unevenness, thus making the evaporation resistance of boundary layer practically independent on the level fabric surface roughness. However, this preliminary conclusion should be confirmed by next systematic research.

7. Incropera FP, DeWitt PD. 2002. Fundamentals of heat and mass transfer. Cornell University, Willey.

8. Hes L. 2008, May. Comments to Heat and Mass Transfer in Skin models Testers of Water Vapour Permeaility of Fabrics. In E.E. D. Adolphe (Ed.) Proceedings of Spring Fiber Society International Conference (110-112). ENSITM Mulhouse, France.

9. Rekova M. 2010. The effect of the fabric structure on its measurement of water vapour permeability according to the ISO 11092 (in Czech, unpublished BSc Thesis). Technical university of Liberec, Liberec.

10. Hes L, Baczek-Boguslawska M. 2018, November. The effect of surface rough ness on determination of water vapour resistance of fabrics tested by a skin model. In E.E. S. Msahli (Ed.) Proceedings of International conference on applied research on textile CIRAT 8 (1314). Monastir, Tunisia.

11. Ahmad HS, Jamshaid H. 2019. Development of thermophysiologically comfortable knit structure for sports applications. Tekstil ve Konfeksiyon 29(2), 105-112. 